\title{
Ipsilateral Femoral Neck and Shaft Fractures
}

\author{
*Daine 0. Clarke \\ Department of Orthopedics, Kingston Public Hospital, Jamaica
}

Submission: March 10, 2017; Published: March 15, 2017

*Corresponding author: Daine 0. Clarke, MBBS, BMedSc (Hon), Department of Orthopedics, Kingston Public Hospital, North St, Kingston, Jamaica, Email: daineoclarke@gmail.com

\begin{abstract}
Ipsilateral fractures of the femoral neck and shaft are usually the result of high-energy trauma. The incidence ranges from 2.5-6\% [13]. With improvements in trauma care the incidence will only increase as the mortality amongst multiple trauma patients decreases. The associated neck fracture is initially missed in up to $33 \%$ of cases $[4,5]$. These patients tend to have multisystem injuries as well as other associated orthopaedic injuries $[2,6]$. There is a $22.6 \%$ associated incidence of open fractures, while injuries involving the knee are seen quite commonly in up to $40 \%$ of cases [5,6].

In managing these patients, the orthopaedic surgeon is confronted with a number of issues as it relates to the management of the multiple trauma patient: the timing of surgery and the subtle differences or additional challenges posed when a neck of femur fracture has an associated shaft fracture. A case is presented here to highlight these management dilemmas.
\end{abstract}

\section{Introduction}

A 36-year-old helmeted pillion rider was thrown from a bike that had collided with a motorcar. He remained conscious throughout, complained of left thigh and hip pain, and was unable to weight bear on the left lower limb. He was haemodynamically stable on presentation. The respiratory, abdomen, pelvic examinations were normal. There was deformity and swelling to the left mid-thigh. No neurovascular deficit was present. The anteroposterior radiograph of the pelvis, inclusive of the proximal femur revealed a transcervical neck of femur fracture. Radiographs of the left femur and knee joint revealed a displaced mid-shaft femoral fracture (Figure 1).

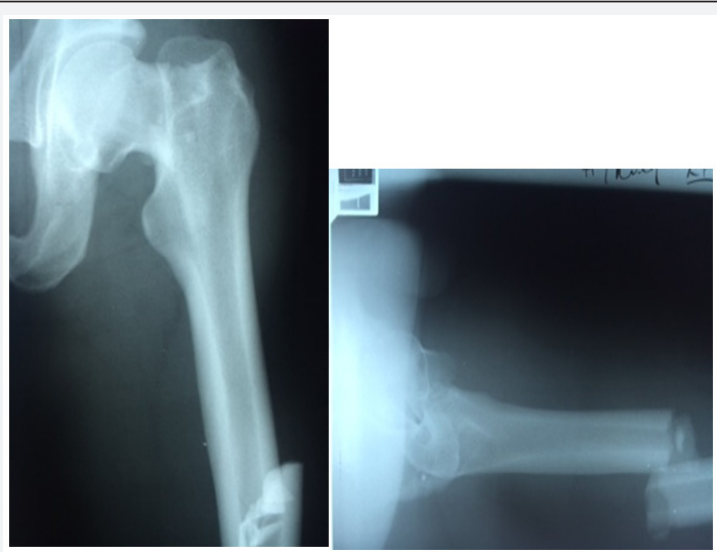

Figure 1: $A P$ and lateral radiograph of left hip showing basic cervical neck of femur fracture with ipsilateral femoral shaft fracture.
Proximal tibial skeletal traction was instituted.

He was taken to the operating theatre within 72 hours of presentation. The decision was made to address each fracture with a separate device. The patient was anaesthetized and positioned on a fracture table. A Steinman pin was inserted transversely across the femoral condyles inferior to the junction of Blumensaat's line with the anterior intercondylar joint line. The knee was flexed to $60^{\circ}$ and traction applied to reduce the shaft fracture. The intercondylar notch was accessed through a medial parapatellar incision and a guide wire was passed across the fracture under fluoroscopic guidance. A reamed, statically locked retrograde nail was inserted.
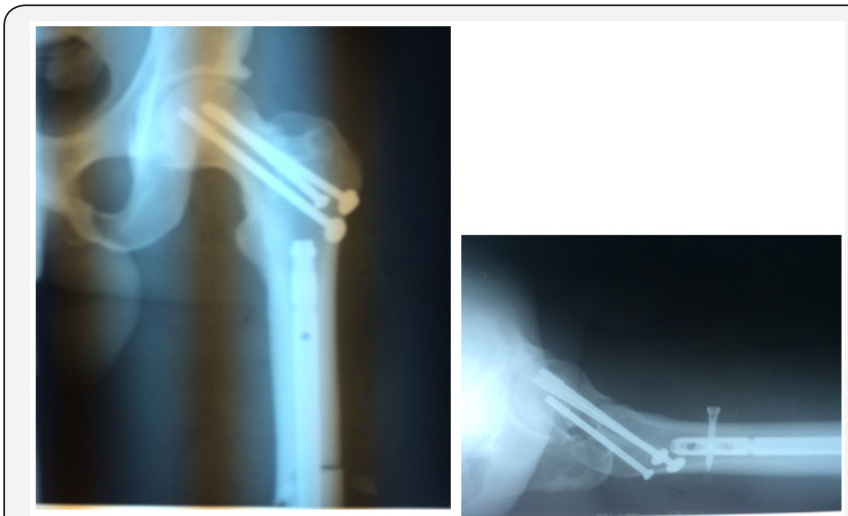

Figure 2: Post-operative radiographs showing retrograde nailing and canulated screw construct for fixation. 


\section{Orthopedics and Rheumatology Open Access Journal}

Manipulation of the now stabilized femoral shaft was utilized to achieve closed reduction of the transcervical neck fracture in conjunction with a Steinman pin inserted in the proximal aspect of the neck of the femur. Three $6.5 \mathrm{~mm}$ cannulated screws were inserted across the transcervical fracture in an inverted triangle configuration (Figure 2).

\section{Discussion}

Ipsilateral femoral neck and shaft fracture was first reported in the literature by Delaney and Street [7]. They remain a rare injury with an incidence of $2.5-6 \%$ but with improvement in trauma care and increased survival rate of the multiple trauma patients, this incidence is likely to increase [5]. The mean age of presentation is 34 years old and is usually seen in high energy injuries [8]. The injury pattern is thought to be due to a higher energy mechanism than isolated neck of femur fracture yet the neck fracture is often un-displaced. The concomitant shaft fracture is often comminuted and or open and is thought to absorb the majority of the force decreasing the forces across the neck explaining the less likelihood of displacement versus isolated neck of femur fractures [4]. The incidence of osteonecrosis in ipsilateral femoral neck and shaft fractures is also less than that of isolated neck of femur fractures, $3-4 \%$ as compared $10-35 \%$ $[5,9]$. This may be representative of lower energy injury pattern and supportive of the above postulate.

The management of isolated femoral neck fractures in the young is geared towards head preservation and has the wellrecognized complications of osteonecrosis, non-union and malunion. To date, several un-answered questions persist today regarding the optimal management of these fractures including the time to surgery, role of capsulotomy and the best implant choice.

When femoral neck fractures are associated with shaft fractures, these unanswered questions come into play as well as the additional task of managing a femoral shaft fracture, choosing the appropriate implant for both fractures and utilizing non-conflicting choices. The choice of implant or fixation of either fracture may compromise fixation of the other [10]. The data on isolated neck of femur and isolated femoral shaft fractures have answered the questions of the best biomechanical choices. These can be extrapolated to ipsilateral injuries however implant choices may not be compatible. As it relates to isolated femoral neck fractures Aminian et al. [11] in their cadaveric studied found that in order of biomechanical stability femoral locking plates gave the most rigid construct followed by dynamic condylar screw, dynamic hip screw and cannulated screws [11]. The femoral locking plate however does not afford compression and this would have to be achieved prior to the placement of the implant. Reamed locked intramedullary nails have become the treatment of choice for isolated femoral shaft fractures for several reasons including biomechanical ones. [12]. Knowledge of the biomechanical strength of these devices maybe employed to concomitant ipsilateral neck and shaft fractures however implant choice must be tailored to accommodate both implants. The use of a single implant construct to address both fractures remains an option however gaining and maintaining two reductions concurrently may prove challenging. Additional disadvantages includes the risk of further displacement of the femoral neck fracture and possibility of further compromising the blood supply based on the proximity of the entry point to fracture, as the entry point may coincide with the fracture location $[6,9]$. Advocates of the single implant approach site benefits of decreased operating time and blood loss as advantages of this approach $[9,13]$. The ideal sequence of fixation also remains unknown. The complications related to the neck of the femur fracture inclusive of avascular necrosis is more devastating than femoral shaft complications therefore fixation of the femoral neck takes precedence. There is no consensus however to the sequence of fixation. Fixation of the shaft fracture prior to the neck fracture allows for greater control of the shaft and may aid reduction of the femoral neck fracture.

Timeline for ideal fixation remains unknown and authors have recommended from within the first 8 hrs to within a week [5,14-17].

\section{Conclusion}

The injury pattern, concomitant ipsilateral fractures of the femoral shaft and neck, presents unique challenges in achieving simultaneous reduction of both fractures. Several methods of fixation have been described and controversy exists regarding the best approach. No approach has been shown to be superior. Complications arising from inadequate management of neck of femur fracture confer greater disability than that of the shaft and should therefore take precedence.

\section{References}

1. Bennett FS, Zinar DM, Kilgus DJ (1993) Ipsilateral hip and femoral shaft fractures. Clinical orthopaedics and related research 296: 168-177.

2. Zettas JP, Zettas P (1981) Ipsilateral fractures of the femoral neck and shaft. Clinical orthopaedics and related research 160: 63-73.

3. Winquist RA, Hansen ST, Clawson DK (1984) Closed intramedullary nailing of femoral fractures. A report of five hundred and twenty cases. The Journal of bone and joint surgery American 66(4): 529-539.

4. Alho A (1996) Concurrent ipsilateral fractures of the hip and femoral shaft: a meta-analysis of 659 cases. Acta orthopaedica Scandinavica 67(1): 19-28.

5. Swiontkowski MF, Hansen ST, Kellam J (1984) Ipsilateral fractures of the femoral neck and shaft. A treatment protocol. The Journal of bone and joint surgery American volume 66(2): 260-268.

6. Wiss DA, Sima W, Brien WW (1992) Ipsilateral fractures of the femoral neck and shaft. Journal of orthopaedic trauma 6(2): 159-166.

7. Delaney WM, Street DM (1953) Fracture of femoral shaft with fracture of neck of same femur; treatment with medullary nail for shaft and Knowles pins for neck. The Journal of the International College of Surgeons 19(3): 303-312.

8. Alho A (1997) Concurrent ipsilateral fractures of the hip and shaft of the femur. A systematic review of 722 cases. Annales chirurgiae et gynaecologiae 86(4): 326-336. 
9. Jain P, Maini L, Mishra P, Upadhyay A, Agarwal A (2004) Cephalomedullary interlocked nail for ipsilateral hip and femoral shaft fractures. Injury 35(10):1031-1038.

10. Cannada LK, Viehe T, Cates CA, Norris RJ, Zura RD, et al. (2009) A retrospective review of high-energy femoral neck-shaft fractures. Journal of orthopaedic trauma 23(4): 254-260.

11. Aminian A, Gao F, Fedoriw WW, Zhang LQ Kalainov DM,et al. (2007) Vertically oriented femoral neck fractures: mechanical analysis of four fixation techniques. Journal of orthopaedic trauma 21(8): 544-548.

12. Bhandari M, Guyatt GH, Tong D, Adili A, Shaughnessy SG (2000) Reamed versus nonreamed intramedullary nailing of lower extremity long bone fractures: a systematic overview and meta-analysis. Journal of orthopaedic trauma 14(1): 2-9.

13. Bedi A, Karunakar MA, Caron T, Sanders RW, Haidukewych GJ (2009) Accuracy of reduction of ipsilateral femoral neck and shaft fractures--an analysis of various internal fixation strategies. Journal of orthopaedic trauma 23(4): 249-253.

14. Parfenchuck TA, Carter LW, Young TR (1993) Ipsilateral fractures of the femoral neck and shaft. Orthopaedic review 22(3): 356-363.

15. Randelli P, Landi S, Fanton F, Hoover GK, Morandi M (1999)Treatment of ipsilateral femoral neck and shaft fractures with the Russell-Taylor reconstructive nail. Orthopedics 22(7): 673-676.

16. Okcu G, Aktuglu K (2003) Antegrade nailing of femoral shaft fractures combined with neck or distal femur fractures. A retrospective review of 25 cases, with a follow-up of 36-150 months. Archives of orthopaedic and trauma surgery 123(10): 544-550.

17. Chaturvedi S, Sahu SC (1993) Ipsilateral concomitant fractures of the femoral neck and shaft. Injury 24(4): 243-246.

\section{Your next submission with Juniper Publishers will reach you the below assets}

- Quality Editorial service

- Swift Peer Review

- Reprints availability

- E-prints Service

- Manuscript Podcast for convenient understanding

- Global attainment for your research

- Manuscript accessibility in different formats

( Pdf, E-pub, Full Text, Audio)

- Unceasing customer service

Track the below URL for one-step submission https://juniperpublishers.com/online-submission.php 